\title{
Mineralogical Variation in Shells of the Blackfoot Abalone, Haliotis iris (Mollusca: Gastropoda: Haliotidae), in Southern New Zealand ${ }^{1}$
}

\author{
Blair E. Gray ${ }^{2}$ and Abigail M. Smith ${ }^{2,3}$
}

\begin{abstract}
The New Zealand blackfoot abalone, Haliotis iris Gmelin, is among the few gastropods that precipitate both calcite and aragonite in their shells. The location, composition, and thickness of these mineral layers may affect color, luster, and strength of the shell, which is locally important in jewelry manufacture. Skeletal mineralogy and shell structure of $H$. iris from three southern New Zealand locations were determined using X-ray diffractometry, scanning electron micrography, and mineral staining. In H. iris an outer calcitic layer is separated from an inner aragonitic surface by both calcified and noncalcified organic layers running longitudinally through the shell. Skeletal mineralogy within individual shells varies from 29 to $98 \%$ aragonite, with older shell having significantly higher aragonite content than young sections. Variation within populations ranges from 40 to $98 \%$ aragonite, and among three populations from 34 to $98 \%$ aragonite. Shell thickness, too, varies within individual shells from 0.2 to $4.2 \mathrm{~mm}$, with a significant positive relationship with age. Withinpopulation variation in shell thickness ranges from 2.1 to $5.4 \mathrm{~mm}$, with no significant difference in shell thickness variation among populations. The high degree of variability within and among individual shells suggests that it is essential to test replicate samples from individual mollusk shells, especially when they have complex bimineral structure.
\end{abstract}

Mollusks Have BeEN secreting mineral skeletons for some 600 million yr. Skeletons may function in detoxification, temporary storage of vital ions, gravity perception, light reflection, navigation, structure, and/or protection from predation (Litivin et al. 1997, Weiner and Addadi 1997). Mollusk shells are usually composed of about $95 \% \mathrm{CaCO}_{3}$ (Belcher et al. 1996, Schaffer et al. 1997) precipitated as one or both of the major crystalline polymorphs: the more thermodynamically stable trigonal calcite and metastable

${ }^{1}$ This research was supported by a New Zealand Ph.D. Graduates in Industry Fellowship (GRIF) from the Foundation for Research, Science, and Technology (FoRST). Manuscript accepted 6 May 2003.

2 Department of Marine Science, University of Otago, P.O. Box 56, Dunedin, New Zealand.

${ }^{3}$ Corresponding author (phone: +64 (3) 479 8306; fax: +64 (3) 479 8336; E-mail: abbysmith@otago.ac.nz).

Pacific Science (2004), vol. 58, no. 1:47-64

(C) 2004 by University of Hawai'i Press

All rights reserved orthorhombic aragonite (Dauphin et al. 1989, Shepherd et al. 1995b, Hawkes et al. 1996). The remaining shell material is an organic matrix composed predominantly of glycoproteins (Weiner and Addadi 1991, Giles et al. 1995).

Most gastropod skeletons are constructed of aragonite (Bøggild 1930, Dauphin et al. 1989). Only a few gastropods, belonging to 13 families, utilize calcite to construct part or all of their shells. Many abalone, including Haliotis iris Gmelin, precipitate polymorphic shells using both aragonite and calcite in shell construction. The genus Haliotis ranges from 50 to $100 \%$ aragonite in bulk shell mineralogy (Lowenstam 1954).

Shell deposition in an abalone occurs primarily at the umbo or spire. A line of pores or breathing holes (the tremata) grows approximately parallel to the outer contour of the shell. The outermost surface of most mollusk shells is a noncalcified proteinaceous organic periostracum (Saleuddin and Petit 1983). This layer is thin in Haliotis spp. (100$200 \mathrm{~nm}$ thick) and may protect the shell from 


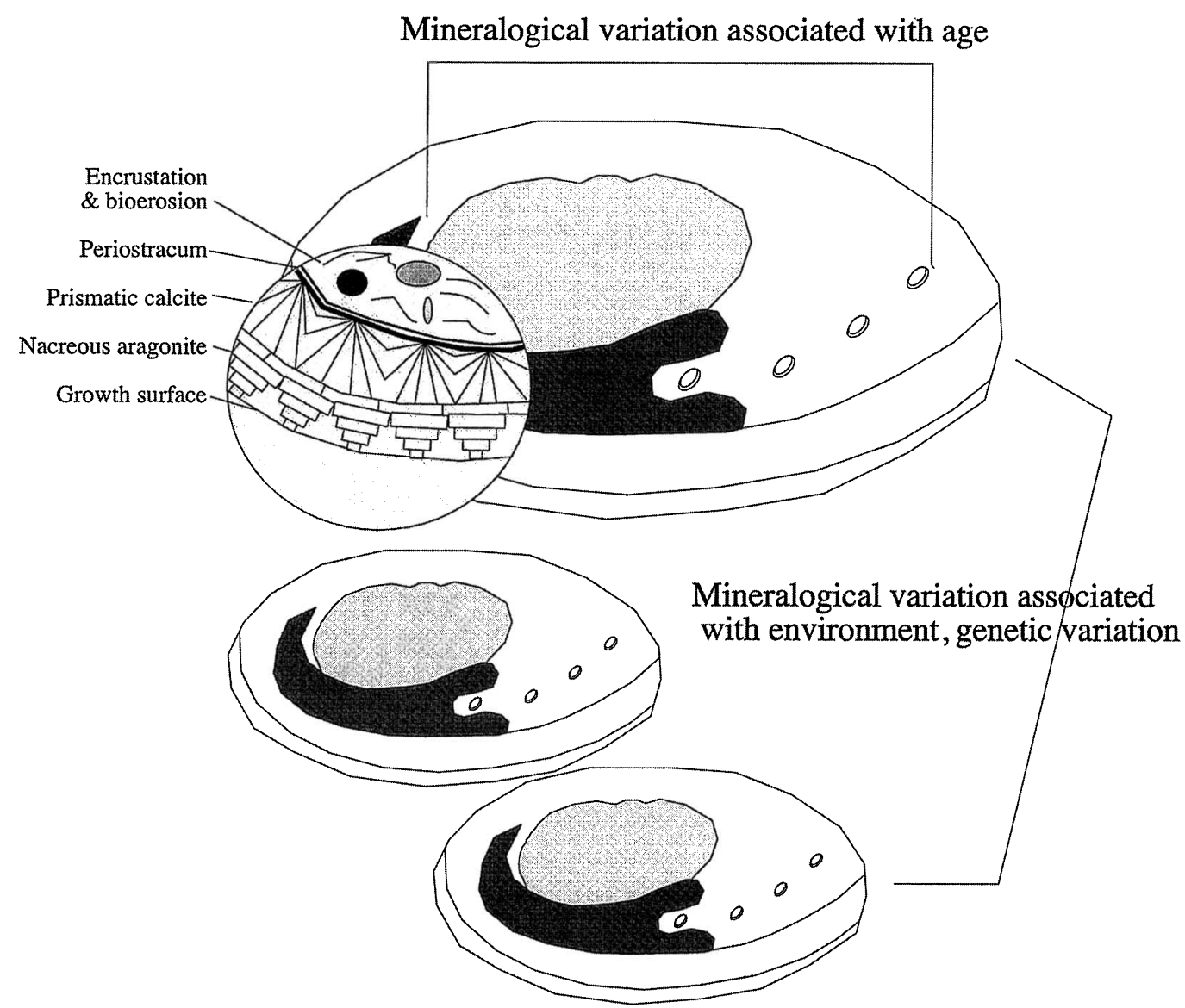

FIGURE 1. Mineralogical structure of Haliotis iris and possible sources of variation.

corrosion by seawater and colonization by epibionts and endobionts (Shepherd et al. 1995a, Schaffer et al. 1997). In most abalone the next layer is prismatic calcite (Figure 1), made up of calcite crystals with a diameter up to $100 \mathrm{~nm}$. In some species, however, this outer layer is aragonitic, and in a few temperate species it is a combination of both calcite and aragonite (Shepherd et al. 1995a). Each individual crystal is surrounded by organic glycoprotein matrix, 0.5 to $3 \mathrm{~nm}$ thick in most adult abalone. An inner layer is composed of tabular nacreous aragonite (Nakahara 1982, Fritz et al. 1994, Shepherd et al. 1995a). The tablets are highly uniform within a species, though there is variation among species (Watabe 1965). In H. iris, the plates are from 300 to $450 \mathrm{~nm}$ thick. Each plate is surrounded by organic matrix, which may be partially calcified. The organic matrix gives the shell exceptional strength, with approximately 3000 times the fracture resistance of pure calcium carbonate (Jackson et al. 1988, Shen et al. 1997). Periodically there is a thicker $(>35 \mu \mathrm{m})$ organic layer of conchiolin deposited along the length of the shell. Stacks of aragonite tablets form the growing edge of the shell. Because new nacreous tablet "seeds" are deposited in the middle of the preceding tablet, the consecutive tablets form pyramidal columns (Schaffer et al. 1997). There is currently much interest in the pro- 
cesses that regulate the structure and growth of this layer (e.g., Carter and Clark 1985, Hawkes et al. 1996, Zaremba et al. 1996, Hedegaard and Wenk 1998, Kaplan 1998, Chateigner et al. 2000) in mollusks.

Variation in gastropod mineralogy at the genus and species levels is well known (Bøggild 1930, Dauphin et al. 1989, Erasmus et al. 1994), but there is very little information about mineralogical variation within species or even within individuals. Although the outer calcitic and an inner aragonite shell layers have been well documented in abalone (e.g., Shepherd et al. 1995a), variations in the thickness and relative proportions of these layers are unknown, though they may have important implications for luster, color, and strength of shell and pearl products. Studies of other shell-bearing taxa have shown that physicochemical conditions (primarily water temperature and salinity) may influence carbonate mineralogy and ultrastructure (Lowenstam and Weiner 1989, Cairns and MacIntyre 1992, Cohen and Branch 1992); it is less clear how wave exposure, predation, and bioerosion affect shell geochemistry (Boulding et al. 1999).

There are approximately 100 species of abalone worldwide (Bevelander 1988). Their natural distribution covers most tropical and temperate coastal marine regions around the world, with the exceptions of South America and eastern North America (Hahn 1989). Three species of abalone, commonly known by the Maori name paua (Tong and Moss 1989), are endemic to New Zealand's coastal waters. Of these species the blackfoot abalone, Haliotis iris, is the largest (7 to $18 \mathrm{~cm}$ at maturity). Blackfoot abalone are generally found in the low intertidal and subtidal zones to $15 \mathrm{~m}$ water depth (Poore 1972, Wilson 1987) around most of the coastline of New Zealand. Although they prefer low sedimentation rates (Wilson 1987) and access to drift seaweeds such as Macrocystis pyrifera upon which they feed (Stuart and Brown 1994), the degree of exposure in which they live varies from sheltered to very exposed environments.

Haliotis iris has been harvested for several hundred years as a traditional food by the Maori people (Wilson 1987) and is the main species in a modern abalone fishery of 1221 tonnes, worth NZD\$66 million in 2000 (New Zealand Seafood Industry Council 2000). In addition, the iridescent and colorful inner surface has created a high demand for abalone jewelry products (Fankboner 1991, Broad 1996) and spurred research into both seeding abalone pearls (Cropp and O'Sullivan 1994, Fankboner 1994, Broad 1996, Fassler 1998) and increasing development of aquaculture. The demand for abalone pearls is high, with some individual pearl products fetching NZD\$3000 (Davies 1996). This is the first detailed study of the thickness and composition of $H$. iris shell from New Zealand.

\section{MATERIALS AND METHODS}

Shells of New Zealand blackfoot paua, Haliotis iris, in the normal adult size range (80$180 \mathrm{~mm}$ ) were collected from three coastal populations in southern South Island, New Zealand (Figure 2). These subtidal populations were from Colac Bay $\left(46^{\circ} 20^{\prime} \mathrm{S}, 167^{\circ}\right.$ $\left.50^{\prime} \mathrm{E}\right)$, Waipapa Point $\left(46^{\circ} 40^{\prime} \mathrm{S}, 168^{\circ} 50^{\prime} \mathrm{E}\right)$, and Moeraki Point (45 $\left.20^{\prime} \mathrm{S}, 169^{\circ} 50^{\prime} \mathrm{E}\right)$, which represent moderately exposed, highly exposed, and highly sheltered environments, respectively.

\section{X-Ray Diffractometry}

Five shells from each of the three populations were dried for at least $72 \mathrm{hr}$. To remove epibiota without disturbing mineralized shell, the exterior of each shell was scraped with a plastic blade. All shells were cleaned in an ultrasonic bath for $1 \mathrm{~min}$ in distilled water (Erasmus et al. 1994), then dried for a further $72 \mathrm{hr}$ before the interior and exterior were photographed using a camera (Nikon 801) with a micro $55-\mathrm{mm}$ lens under D65K lights to visually record the extent of encrustation and biodegradation.

Entrapment of nonabalone material such as organic matter and sand in empty endolithic borings is a possible source of error. Excessive organic matter can interfere with X-ray diffractometry (XRD) traces, causing suppression and masking of peaks. Reduc- 


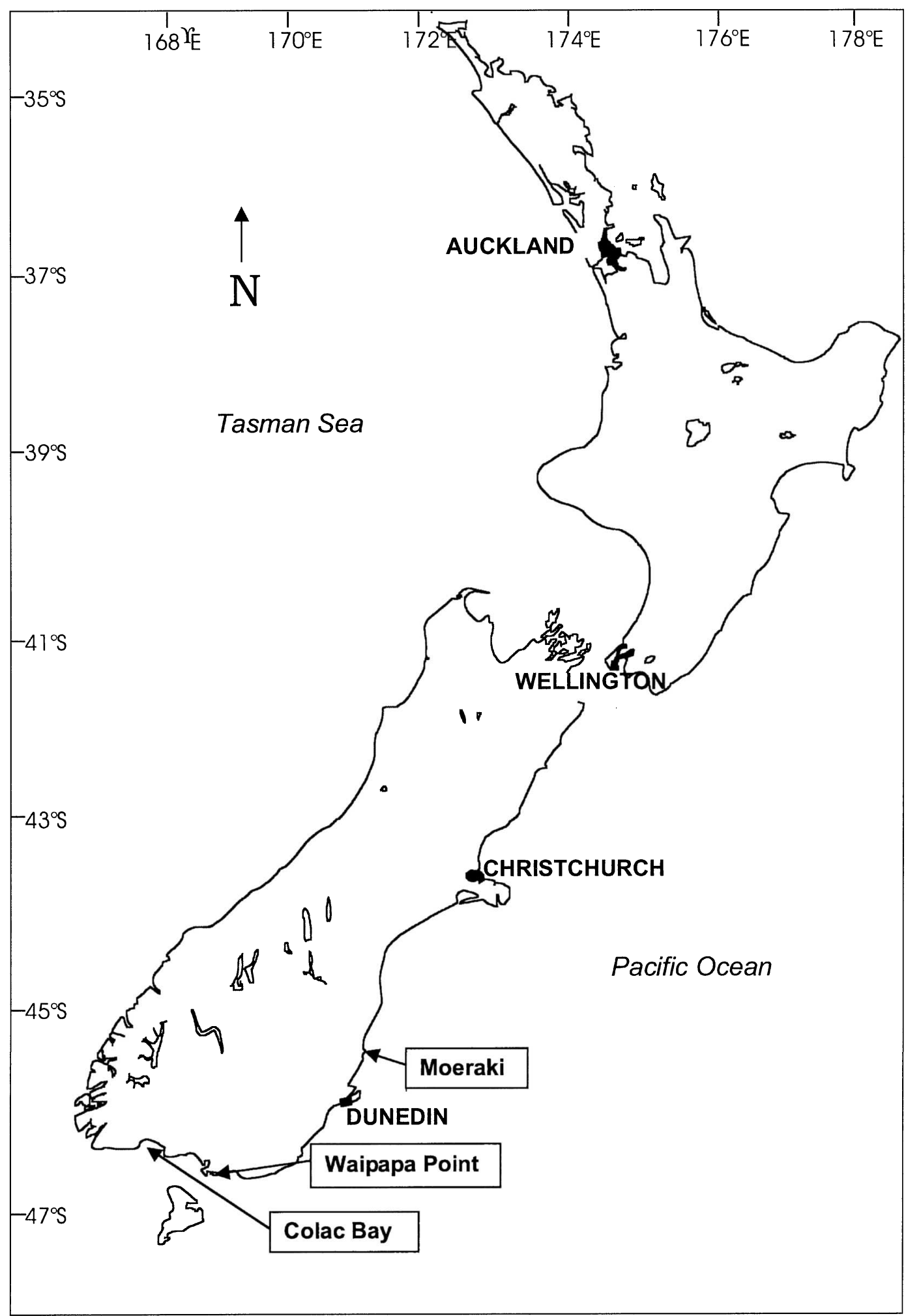

Figure 2. Study sites at Moeraki, Waipapa Point, and Colac Bay in southern New Zealand. 
tion of organic content by soaking in sodium hypochlorite (NaOCl) (Smith et al. 1998, Wright and Schwarcz 1998) causes no dissolution of $\mathrm{CaCO}_{3}$ detectable by scanning electron microscopy (SEM) (Gaffey and Bronnimann 1993), but because bleaching can damage calcified membranes and affect crystalline structure (Carriker 1979, Mutvei 1983) we did not bleach these shells (Mutvei 1983). Sediment trapped in the shell did not cause interference with either XRD or Feigl's analyses. Quartz, the main constituent of local sediment, has major XRD peaks at 4.2574 (100), 3.3446 (101), and 2.2818 (012) ${ }^{\circ} 2 \theta$, sufficiently far from the aragonite (111) and (021) and calcite (104) peaks used in this analysis to avoid interference.

A grid was drawn on the exterior of each shell, with five segments (A to E) oriented along the length and four (1 to 4 ) across the width of the shell (Figure 3). The size of each of the 20 segments was thus proportional to the size of the shells. A diamond-tipped geologic band saw was used to section the dry shells. Shell thickness was measured by examining shell sections under a low-power microscope. Each shell section was then powdered in a grinding head (TEMA) for approximately $45 \mathrm{sec}$. The grinding head was cleaned with silica sand between samples to reduce cross-sample contamination. Minimal grinding (Moore and Reynolds 1997) was used to increase the accuracy of quantitative $\mathrm{XRD}$ analysis and reduce the possibility of

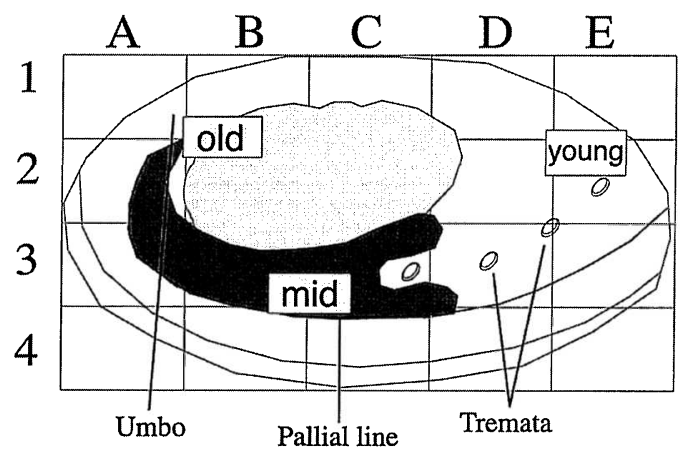

FIGURE 3. Haliotis iris shell showing the grid used for sectioning shells into rows (1 to 4 ) and columns (A to E) before XRD analysis and the three age sections (old, mid, and young) removed for mineral staining. reversion of aragonite to calcite (Davies and Hooper 1963, Cohen and Branch 1992).

Approximately $0.5 \mathrm{~g}$ of well-mixed sample powder was placed in a clean mortar with $0.1 \mathrm{~g}$ analytical-grade $\mathrm{NaCl}$ as an internal standard and a small amount of distilled water. The solution was mixed with a pestle until even in texture and color, and then a portion was smeared on a glass slide until there was even coverage over an area of 20 by $20 \mathrm{~mm}$. The slide was tapped gently to remove any air bubbles and dried slowly under a lamp.

An X-ray diffractometer (Philips PW1050) with a $\mathrm{Cu}$ target $\mathrm{X}$-ray source scanned each sample between 25 and $35^{\circ} 2 \theta$. There were 50 counts per degree and the count time was $1 \mathrm{sec}$. In the range $25-35^{\circ} 2 \theta$ there are three main aragonite peaks, with $\mathrm{d}$ spacings as follows (Miller's indices in parentheses): $\mathrm{d}_{\mathrm{A} 1}=$ $3.397(111), \mathrm{d}_{\mathrm{A} 2}=3.274(021)$, and $\mathrm{d}_{\mathrm{A} 3}=$ 2.702 (012). The calcite and halite peaks are at $\mathrm{d}_{\mathrm{C}}=3.035$ (104) and $\mathrm{d}_{\mathrm{H}}=2.821$ (200), respectively.

A calibration curve for the proportions of calcite and aragonite was developed using shell material from two monomineralic mollusks: the calcitic oyster Crassostrea glomerata and the aragonitic cockle Astrovenus stutchburyi. The calibration curve was developed following protocols similar to those used by Davies and Hooper (1963) and Smith et al. (1998), particularly taking into account their recommendation to use similar biogenic minerals for calibration, rather than analyticalgrade synthetic calcite and aragonite. The best calibration curve (several different measures were tested) had a $R^{2}$ of 0.99 and was:

$$
\begin{aligned}
& \text { Wt } \% \text { calcite } \\
& \quad=80.4(\mathrm{PR})^{2}-180.9(\mathrm{PR})+101.2
\end{aligned}
$$

where PR (peak height ratio) is the sum of the maximum peak heights measured from the base line for aragonite $\mathrm{d}_{\mathrm{A} 1}$ and $\mathrm{d}_{\mathrm{A} 2}$ divided by the sum of aragonite peak heights and the peak height of calcite $\mathrm{d}_{\mathrm{C}}$. Peak height ratios were used rather than peak intensity or other more complicated methods (e.g., Cohen and Branch [1992]) because diffractograms showed sharp clear peaks indicating a welldefined crystallinity (Balmain et al. 1999). 


\section{Carbonate Staining}

Feigl's solution is one of a variety of mineral stains that is used to quickly establish the mineralogy of an unknown sample (Sandberg 1971, Lewis and McConchie 1994). Feigl's solution is a mixture of hydrated $\mathrm{MnSO}_{4}$ and $\mathrm{Ag}_{2} \mathrm{SO}_{4}$ in a very dilute $\mathrm{NaOH}$ base. The reagent preparation was based on the method outlined by Lewis and McConchie (1994). A solution of $11.8 \mathrm{~g} \mathrm{MnSO} 4 \cdot 7 \mathrm{H}_{2} \mathrm{O}$ in $100 \mathrm{ml}$ of deionized water was heated to boiling point, and then $1 \mathrm{~g}$ of commercial $\mathrm{Ag}_{2} \mathrm{SO}_{4}$ was added. After the solution was cool, 1-2 drops dilute $(10 \%) \mathrm{NaOH}$ was added and then left to stand for 1-2 hr. After mixing the solution, the precipitate was filtered out by drawing the solution through $10-\mu \mathrm{m}$ filter paper under vacuum and the solution stored in a dark bottle.

Five additional shells from each of the three populations were cleaned of encrusting biota by either scraping and/or soaking in dilute bleach $(\mathrm{NaOCl})$, taking care not to damage or remove calcified layers. The shell was rinsed in distilled water and shell sections were cut from the shell using a jewelrycutting tool at slow speed to reduce heating. Three sections were removed from each shell: old (adjacent to the spire), mid (halfway along the tremata), and young (adjacent to the intersection of the tremata and growing edge) (Figure 3). The shell edge for staining was etched with $4-6 \% \mathrm{HCl}$ for $30-60 \mathrm{sec}$ at room temperature, or less if effervescence was excessive.

The shell edge was rinsed in distilled water, placed in hot $\left(70-90^{\circ} \mathrm{C}\right)$ Feigl's solution for 5 to $10 \mathrm{~min}$, and rinsed again with distilled water before inspection under a light microscope. Aragonite was stained black, but calcite remained colorless. The thickness and sequence of stained and unstained layers was determined at five sites across each stained section. These data were transformed into proportions to determine percentage aragonite of the shells.

To allow a quantitative comparison of the staining and XRD, the shell sections that were used for Feigl's staining were cleaned by light abrasion to remove the stain and washed under distilled water. The proportions of calcite and aragonite were assessed using XRD following the protocols described earlier in the section on XRD.

\section{Statistical Analysis}

None of the data was transformed before analysis because examination of the appropriate residual plots indicated that this was not necessary. A post hoc test, Fisher's 5\% least significant difference (LSD), was used to examine which groups within a factor were significantly different. The General Linear Model analysis of variance (ANOVA) in Minitab was used for analysis of shell thickness data with a balanced nested design where shells were nested in location and the interaction between location and age was also examined (Sokal and Rohlf 1995).

Percentage aragonite data from the mineral maps were analyzed using a Bonferroni General Linear Model (GLM) producing the very conservative Greenhouse-Geisser test statistic. The mean square (MS) was calculated from a type III sum of squares.

The statistical analysis of the data from Feigl's staining was more straightforward than the "mineral map" analysis developed for the XRD data. The Minitab General Linear Model ANOVA used a balanced nested design where shells were nested in location and the interaction between location and age was examined (Sokal and Rohlf 1995). In addition, individual shells were treated as random factors or effects (Zar 1984, Dytham 1999).

\section{RESULTS}

\section{Shell Characteristics}

Thickness of Haliotis iris shells ranged from $1.7 \mathrm{~mm}$ from a Moeraki "old" section to 7.0 mm from a Colac Bay "old" section. As expected, individual shells showed a clear trend of increasing shell thickness with age. Young shell was thinner $(2.7 \pm 0.9 \mathrm{~mm})$ than both middle age and older shell $(3.3 \pm 0.1$ and $3.7 \pm 0.3 \mathrm{~mm}$, respectively). These differences are highly significant (Table 1).

The least variation in shell thickness within an individual shell was $0.3 \mathrm{~mm}$ in young, 
TABLE 1

Patterns in Shell Thickness of Haliotis iris from Three Locations in Southern New Zealand

\begin{tabular}{|c|c|c|c|c|c|c|c|}
\hline Location & Age & & Mean Thickness $(n=5)$ & & $\mathrm{SE}$ & & Location Mean $( \pm \mathrm{SE})$ \\
\hline \multirow[t]{3}{*}{ Moeraki } & Old & & 3.4 & & 0.83 & & \multirow{3}{*}{$3.00 \pm 0.89$} \\
\hline & Mid & & 3.0 & & 1.02 & & \\
\hline & Young & & 2.6 & & 0.76 & & \\
\hline \multirow[t]{3}{*}{ Colac Bay } & Old & & 3.5 & & 0.43 & & \multirow{3}{*}{$3.30 \pm 0.85$} \\
\hline & Mid & & 3.2 & & 0.59 & & \\
\hline & Young & & 2.2 & & 0.58 & & \\
\hline \multirow[t]{3}{*}{ Waipapa Point } & Old & & 3.1 & & 0.31 & & \multirow{3}{*}{$3.42 \pm 0.69$} \\
\hline & Mid & & 3.2 & & 0.44 & & \\
\hline & Young & & 2.9 & & 0.89 & & \\
\hline Source of variation & & $\mathrm{df}$ & MS & $F$ & & $P$ & Significance \\
\hline Location & & 2 & 310 & 0.34 & & 0.721 & ns \\
\hline Shell (location) error & & 12 & 921 & 6.77 & & $<0.001$ & ** \\
\hline Age & & 2 & 2,098 & 15.40 & & $<0.001$ & ** \\
\hline Location $\times$ age interaction & & 4 & 409 & 3.01 & & 0.019 & * \\
\hline Error & & 204 & 136 & & & & \\
\hline
\end{tabular}

Note: Five specimens from each of three populations were subsampled according to age of shell (see Figure 3). Results of a two-way ANOVA are included.

fairly thin shell (range, 1.9-2.2 $\mathrm{mm}$ ). The largest range in shell thickness was $4.2 \mathrm{~mm}$ (range, $2.8-7.0 \mathrm{~mm}$ ). Overall old shell had the greatest variation in mean shell thickness.

Variation in thickness among shells was greatest at Colac Bay (range, $3.5 \mathrm{~mm}$ ). Moeraki shells also displayed a relatively high degree of variation in average shell thickness $(2.4 \mathrm{~mm})$. Shells from Waipapa Point had the most consistent thickness, with a range of 0.6 $\mathrm{mm}$. These differences are highly significant (Table 1).

Mean shell thickness was surprisingly consistent among the three study locations, with the mean shell thickness in the range 3.0-3.4 $\mathrm{mm}$ (Table 1). Shells from Moeraki were the thinnest (mean $3.0 \pm 0.9 \mathrm{~mm}$ ), and Waipapa Point shells were the thickest $(3.4 \pm 0.7 \mathrm{~mm})$, but these differences are not significant. It is interesting that the interaction of location and age is significant (Table 1), indicating that how shell thickness changed with age varied among the three populations.

\section{Carbonate Mineralogy}

Aragonite in $H$. iris shells varied from 29 to $98 \%$. The oldest shell (sections A2 and A3, see Figure 3) tends to have a higher percentage of aragonite compared with younger shell (sections E1 and E2) (Table 2). Mean aragonite content in each shell section is illustrated graphically for each study location (Figure 4). In the oldest shell, the mean percentage aragonite ranges between $69 \pm 6$ and $85 \pm 3 \%$. The mean percentage aragonite decreases to between $41 \pm 7$ and $65 \pm 5 \%$ in young shell.

Statistical analysis of aragonite content using the conservative Greenhouse-Geisser test statistic revealed highly significant variation within shells, both among rows 1 to $4{ }^{* *} P<$ $0.001)$ and among columns $\mathrm{A}$ to $\mathrm{E}\left({ }^{* *} P<\right.$ 0.001) (Table 2). There was also a highly significant difference for row-column interaction ( $\left.{ }^{* *} P<0.001\right)$, indicating a cross-shell trend in aragonite, probably age-related.

There are no significant differences in aragonite content among the three locations. Trends in aragonite content, however, do differ among the populations. Separate analyses of the data from each of the three locations using ANOVAs (Table 2) showed that highly significant differences occur between rows $\left({ }^{* *} P=0.007\right)$ and columns ${ }^{* * *} P=$ 0.001) for the Colac Bay shells and Waipapa 
TABLE 2

Aragonite Content in Haliotis iris Shells from Three Locations in Southern New Zealand

\begin{tabular}{|c|c|c|c|c|c|c|c|c|c|c|c|c|c|c|c|c|c|}
\hline \multirow[b]{2}{*}{ Location } & & \multicolumn{3}{|c|}{ A } & \multicolumn{3}{|c|}{ B } & \multicolumn{3}{|c|}{$\mathrm{C}$} & \multicolumn{3}{|c|}{$\mathrm{D}$} & \multicolumn{3}{|c|}{$\mathrm{E}$} & \\
\hline & & Mean & Min. & Max. & Mean & Min. & Max. & Mean & Min. & Max. & Mean & Min. & Max. & Mean & Min. & Max. & \\
\hline Colac & 1 & $52 \pm 2.6$ & 45 & 57 & $48 \pm 4.0$ & 38 & 61 & $51 \pm 4.9$ & 36 & 59 & $49 \pm 7.7$ & 35 & 78 & $41 \pm 6.5$ & 29 & 65 & \\
\hline \multirow{3}{*}{ Bay } & 2 & $69 \pm 6.1$ & 50 & 83 & $61 \pm 3.3$ & 51 & 71 & $57 \pm 3.6$ & 47 & 65 & $58 \pm 6.4$ & 38 & 78 & $49 \pm 6.3$ & 33 & 65 & \\
\hline & 3 & $76 \pm 5.2$ & 57 & 84 & $73 \pm 5.0$ & 58 & 85 & $62 \pm 4.0$ & 49 & 74 & $57 \pm 5.4$ & 40 & 70 & $49 \pm 6.5$ & 33 & 66 & $\begin{array}{l}\text { Overall mean } \\
\quad=58.6 \pm 3.16\end{array}$ \\
\hline & 4 & $72 \pm 4.4$ & 59 & 84 & $73 \pm 4.2$ & 59 & 85 & $60 \pm 3.7$ & 50 & 71 & $53 \pm 4.6$ & 45 & 69 & $49 \pm 5.3$ & 34 & 62 & $\begin{array}{l}\text { Mean range } \\
\quad=27.3\end{array}$ \\
\hline \multirow[t]{4}{*}{ Moeraki } & 1 & $66 \pm 1.0$ & 65 & 70 & $65 \pm 3.2$ & 59 & 77 & $67 \pm 6.7$ & 48 & 84 & $66 \pm 4.6$ & 52 & 80 & $62 \pm 3.5$ & 54 & 72 & \\
\hline & 2 & $82 \pm 1.5$ & 79 & 86 & $64 \pm 3.6$ & 56 & 75 & $62 \pm 3.8$ & 47 & 68 & $62 \pm 2.2$ & 59 & 71 & $65 \pm 5.4$ & 53 & 79 & \\
\hline & 3 & $82 \pm 4.9$ & 66 & 90 & $66 \pm 7.1$ & 36 & 77 & $67 \pm 3.1$ & 60 & 76 & $64 \pm 3.3$ & 54 & 72 & $69 \pm 5.0$ & 60 & 88 & $\begin{array}{l}\text { Overall mean } \\
\quad=70.0 \pm 2.53\end{array}$ \\
\hline & 4 & $80 \pm 5.1$ & 67 & 90 & $82 \pm 2.6$ & 75 & 89 & $71 \pm 5.6$ & 52 & 85 & $74 \pm 1.8$ & 71 & 81 & $80 \pm 4.4$ & 65 & 92 & $\begin{array}{l}\text { Mean range } \\
\quad=20.9\end{array}$ \\
\hline Waipapa & 1 & $58 \pm 9.5$ & 45 & 92 & $52 \pm 10.4$ & 44 & 97 & $53 \pm 10.2$ & 44 & 93 & $51 \pm 9.7$ & 40 & 95 & $42 \pm 11.7$ & 38 & 97 & \\
\hline \multirow[t]{3}{*}{ Point } & 2 & $80 \pm 4.8$ & 70 & 95 & $71 \pm 6.9$ & 49 & 89 & $63 \pm 8.6$ & 46 & 95 & $64 \pm 8.2$ & 56 & 93 & $49 \pm 10.3$ & 40 & 93 & \\
\hline & 3 & $85 \pm 3.1$ & 75 & 92 & $73 \pm 4.3$ & 63 & 90 & $64 \pm 8.4$ & 46 & 95 & $66 \pm 9.7$ & 54 & 97 & $53 \pm 10.0$ & 39 & 95 & $\begin{array}{l}\text { Overall mean } \\
\quad=69.0 \pm 4.15\end{array}$ \\
\hline & 4 & $74 \pm 4.7$ & 64 & 92 & $75 \pm 4.3$ & 70 & 95 & $68 \pm 6.4$ & 59 & 94 & $55 \pm 8.6$ & 52 & 98 & $58 \pm 8.5$ & 52 & 97 & $\begin{array}{l}\text { Mean range } \\
\quad=41.9\end{array}$ \\
\hline
\end{tabular}

\begin{tabular}{|c|c|c|c|c|c|c|c|c|c|c|c|c|c|c|c|}
\hline & \multicolumn{5}{|c|}{ Colac Bay } & \multicolumn{5}{|c|}{ Moeraki } & \multicolumn{5}{|c|}{ Waipapa Point } \\
\hline & $\mathrm{df}$ & MS & $F$ & $P$ & Sig. & $\mathrm{df}$ & MS & $F$ & $P$ & Sig. & df & MS & $F$ & $P$ & Sig. \\
\hline Row & 2.04 & $2,515.2$ & 9.75 & 0.007 & ** & 1.56 & $1,090.5$ & 2.73 & 0.144 & ns & 1.80 & $1,804.4$ & 5.05 & 0.045 & * \\
\hline Error (Row) & 8.15 & 257.8 & & & & 6.23 & 398.3 & & & & 7.20 & 357.0 & & & \\
\hline Column & 1.95 & $1,765.2$ & 18.52 & 0.001 & ** & 1.77 & $1,253.4$ & 9.05 & 0.012 & * & 1.28 & $2,219.5$ & 9.49 & 0.024 & * \\
\hline Error (Column) & 7.80 & 95.3 & & & & 7.08 & 138.4 & & & & 5.12 & 233.7 & & & \\
\hline Row $\times$ Column & 2.36 & 522.7 & 2.33 & 0.146 & ns & 3.36 & 476.9 & 2.22 & 0.129 & ns & 2.50 & 285.3 & 1.31 & 0.320 & ns \\
\hline Error $($ Row $\times$ Col $)$ & 9.45 & 88.4 & & & & 13.42 & 215.0 & & & & 9.99 & 217.9 & & & \\
\hline
\end{tabular}

Note: Five specimens from each location were divided into 20 segments ( $\mathrm{A} 1$ to E4), with the mean aragonite content given ( $\pm \mathrm{SE}$ ). The shells are oriented with the umbo in $\mathrm{A} 2-\mathrm{A} 3$, and the growing edge intersects with the tremata in E3-E4 (see Figure 3). ANOVA results on untransformed data are included. 

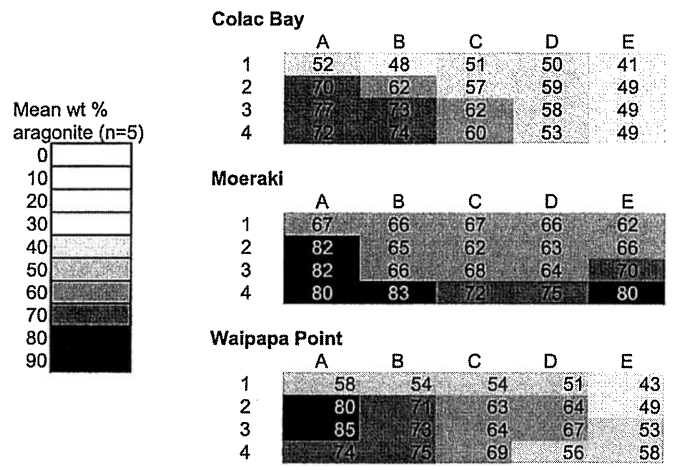

Figure 4. Aragonite content (wt \% aragonite) in $20 \mathrm{sec}-$ tions of Haliotis iris from three locations in New Zealand. The mean for each section is derived from five specimens collected at each location. The shells are oriented with the umbo in $\mathrm{A} 2-\mathrm{A} 3$, and the growing edge intersects with the tremata in E3-E4 (see Figure 3).

Point shells $\left({ }^{*} P_{\text {rows }}=0.045\right)$ and $\left({ }^{*} P_{\text {columns }}=\right.$ $0.024)$. Less variation among shells from Moeraki is evident, with only the columns being significantly different $\left({ }^{*} P=0.012\right)$. There are no significant interactions between rows and columns within any of the locations.

The mean percentage of aragonite for Colac Bay shells was $58 \pm 3 \%$ (Table 2). Aragonite content was higher for shells from both Moeraki $(70 \pm 3 \%)$ and Waipapa Point $(69 \pm 4 \%)$. The difference in the range of aragonite content is striking. Colac Bay and Moeraki shells had a range of 27 and $21 \%$, respectively, whereas the range for the shells from Waipapa Point was much higher (42\%).

These results show that there is both intershell and intrashell variation in aragonite content in $H$. iris from southern New Zealand. There is also some interpopulation difference in the distribution and range of aragonite content at three different locations.

\section{Carbonate Staining}

The thickness of the outer calcitic layer, as determined by staining, varied within individuals, among individuals of a population, and among populations. In both the Colac Bay and Waipapa Point populations, thickness of the calcitic layer within a shell decreased significantly with increasing age
(Figure 5, Table 3). For example, calcite layer thickness in shells from Waipapa Point ranged from a mean of $0.2 \mathrm{~mm}$ in old shell to a mean of $1.5 \mathrm{~mm}$ in young shell. Shells from Moeraki did not, however, show this trend in calcitic layer thickness with age: shell was close to $1.2 \mathrm{~mm}$ thick regardless of age. It is interesting to note that the aragonite layer, in contrast to calcite, increases in thickness with increasing age.

Feigl's staining has not been commonly used for quantitative assessment of mineralogy. It is, however, possible to determine calcite: aragonite ratio using mineral staining, though it gives the data at a single point and is subject to some interpretation. We chose to rely on XRD mineralogical analysis, but it is interesting to note that the overall trend in the staining data confirmed the trends in the XRD data. For both Colac Bay and Waipapa Point populations, the slopes of the regressions are very close to 1 (Figure 6), with $R^{2}$ values greater than 0.8 indicating a good fit. The Moeraki population regression shows a slope of 0.79 , demonstrating the poorer correlation between methods, perhaps due to inclusion of encrusting calcified algae in the abalone shell calcite layer. Although the slopes of these regressions are close to 1 , the $y$-intercept for all three regressions is negative, indicating that staining consistently undermeasures aragonite content.

\section{DISCUSSION}

\section{Shell Characteristics}

Feigl's staining confirms that Haliotis iris, like many abalone, possesses an outer calcitic layer and an inner aragonitic one. There is no evidence of inversion of layers (e.g., a calcite layer surrounded by two aragonite ones, which is reported for some abalone species [Shepherd et al. 1995a, Zaremba et al. 1996]). A detailed description of ultrastructure in $H$. iris will appear in a future paper (in prep.).

Total shell thickness was consistently about 3.0 to $3.5 \mathrm{~mm}$ (Table 1), with standard error around $0.3 \mathrm{~mm}$. There was individual variation regardless of growing environment, which is not surprising because even in an 


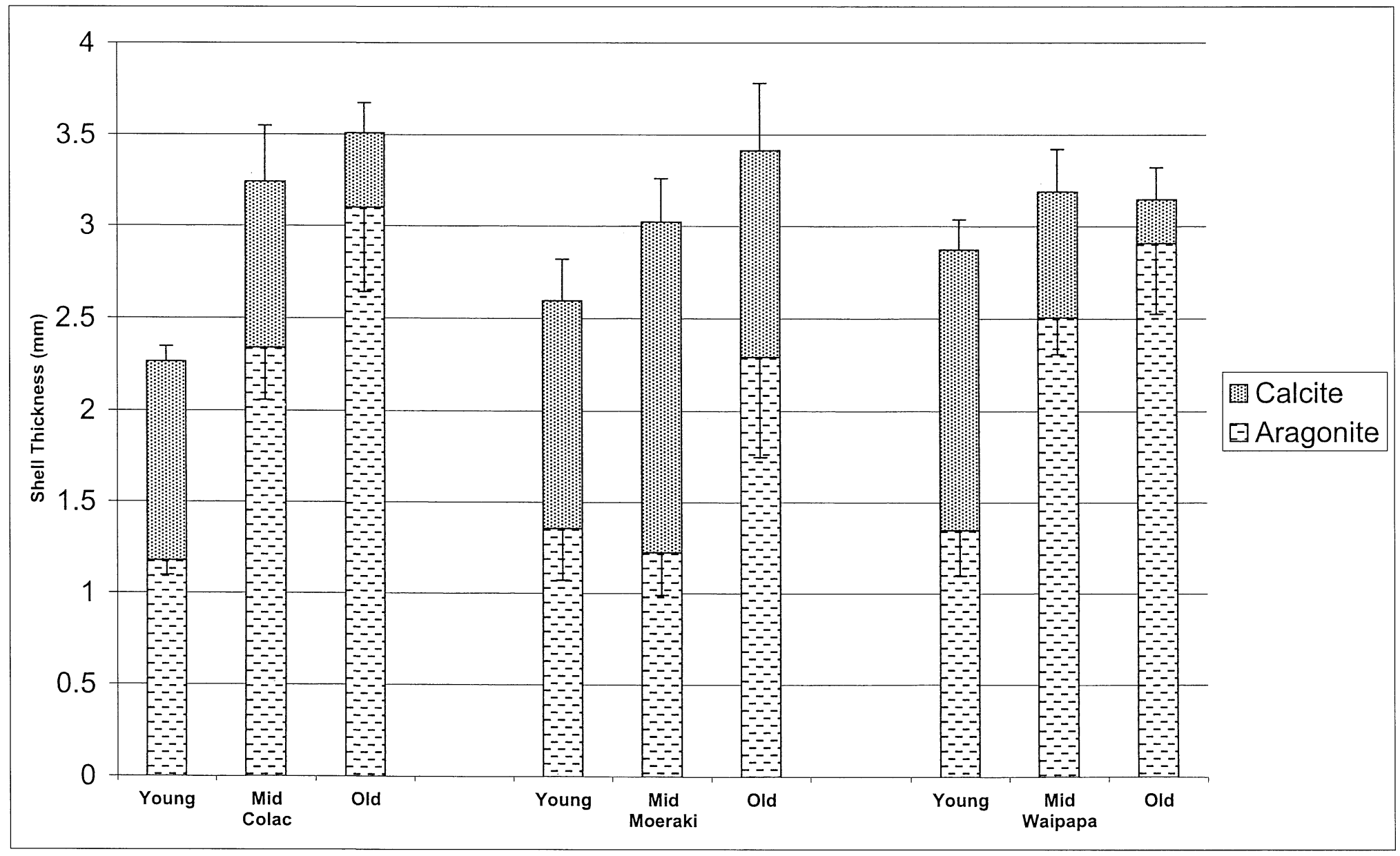

FIgURE 5. Thickness of calcite and aragonite layers in Haliotis iris shell stained with Feigl's mineral stain (mean shell thickness \pm SE, $n=5$ ). 
TABLE 3

Three One-Way ANOVA Tests of Shell Segment Age (Old, Mid, Young) versus Thickness of Outer Calcitic Shell Layers for Haliotis iris (See Figure 5) in Southern New Zealand

\begin{tabular}{|c|c|c|c|c|c|}
\hline Location & df & MS & $F$ & $P$ & Significance \\
\hline Colac Bay & 2 & 75.83 & 20.01 & $<0.001$ & $* *$ \\
\hline Error & 9 & 3.79 & & & \\
\hline Moeraki & 2 & 57.60 & 57.60 & 2.32 & ns \\
\hline Error & 9 & 24.90 & & & \\
\hline Waipapa Point & 2 & 235.00 & 21.11 & $<0.001$ & $* *$ \\
\hline Error & 9 & 11.1 & & & \\
\hline
\end{tabular}

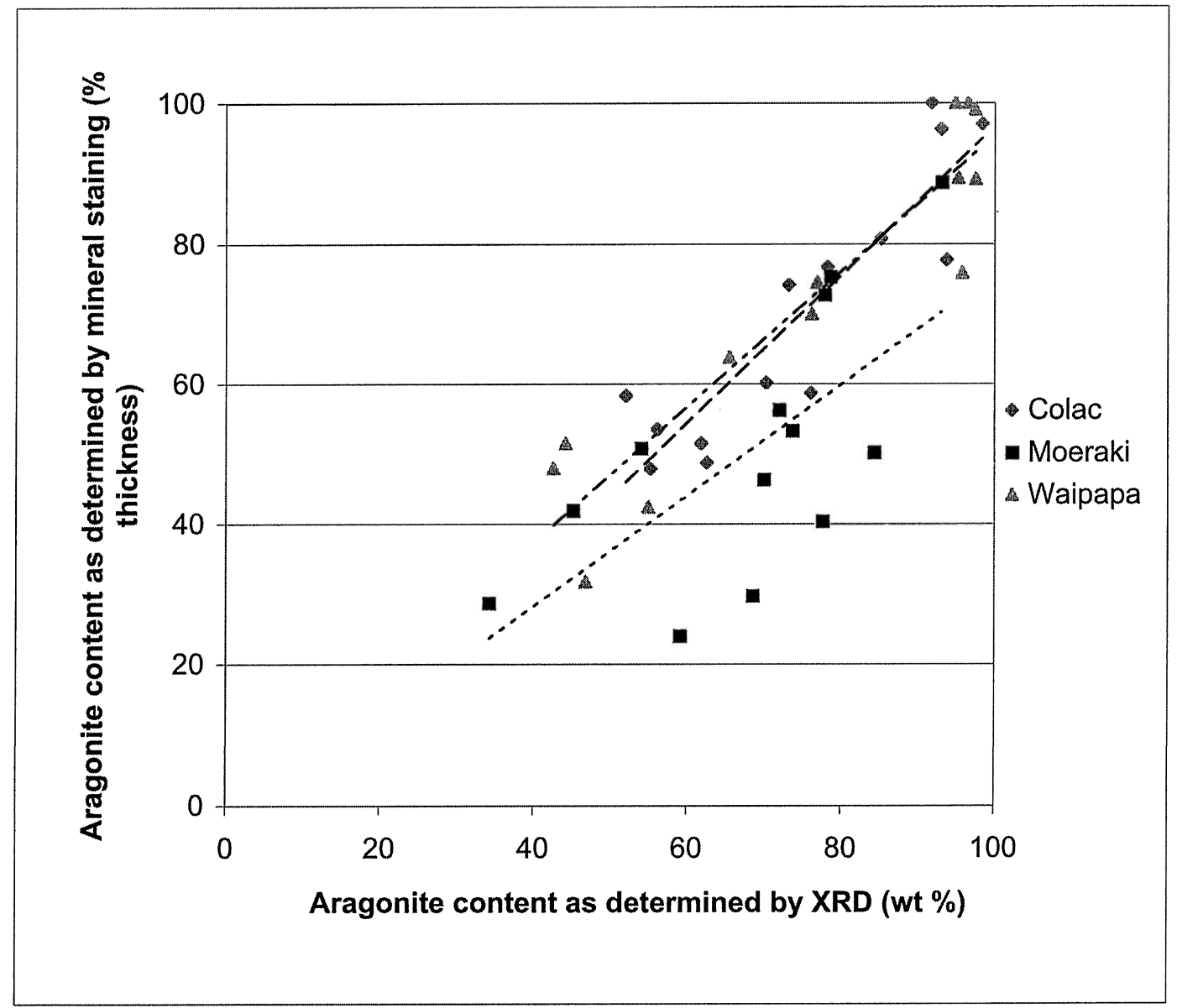

FIgure 6. Comparison of aragonite content in Haliotis iris shell from three locations as measured using XRD and Feigl's mineral stain. Regression equations: Colac Bay, $y=1.06 x-9.12\left(R^{2}=0.81\right)$; Moeraki, $y=0.80 x-$ $3.35\left(R^{2}=0.45\right)$; Waipapa Point, $y=0.97 x-1.41\left(R^{2}=0.86\right)$. 
environmentally controlled hatchery or landbased abalone farm the same cohort may demonstrate a wide range of growth characteristics, with some individuals increasing shell length at three times the rate of others (Gray 1998). For wild abalone, the range in shell thicknesses has a number of possible explanations: different ages of the animals, differing microhabitats within a population, and different genetic growth characteristics.

It is not surprising that shell thickness increased with age. Rate of shell growth may be influenced by physical, chemical, or biological factors, which may include breakage and abrasion, dissolution and metabolic calcification rate, encrustation, and bioerosion. In addition, there may be interactions of effects such as protection of the shell from physical abrasion by encrusters. Shell abrasion is similar to erosion (sensu Day et al. 2000), encompassing the effects of wave action and sand scour. Seawater with unusually low alkalinity, low $\mathrm{pH}$, and/or low salinity may affect not only shell dissolution but also the ability of abalone to form new shell. Inorganic calcification is seldom seen in temperate waters but may be important in warmer water environments. The effect of abrasion on the thickness of haliotid shells has been noted but not quantified elsewhere (Shepherd et al. 1995a). Once the outer organic periostracum has been eroded or breached by shell borers, dissolution of the shell by ambient seawater is possible (Harper 1997).

The exterior surface of $H$. iris shell differed among the three study locations. Shells from Waipapa Point were virtually devoid of any encrusting flora or fauna, supporting only a few filamentous chlorophytes and a few tube worms and/or barnacles. The outer calcitic layer on many shells was extensively bored, up to 25 burrows per square centimeter, especially around the umbo, sometimes to such an extent that the calcitic layer was eroded and the nacreous aragonitic layer was visible. Shells from Colac Bay were similarly bored but supported 5 to 10 encrusting invertebrates: barnacles, tube worms, chitons, and limpets. In contrast, shells from Moeraki supported thick encrustation, often by more than 10 organisms, including calcified algae up to $30 \mathrm{~mm}$ thick, other Chlorophyta and Rhodophyta, bryozoans, tube worms, limpets, and barnacles. Boring in the calcitic layer was extensive, much as in the Waipapa Point shells. Shells from all locations exhibited a great deal more shell boring in the outer calcitic layer than in the inner nacreous layers.

Calcified algal encrusters may have influenced measured abalone shell thickness, especially in the Moeraki site. Although as many epibiota as possible were removed, algal calcite is very similar to abalone shell in physical appearance and it was difficult to assess where they intersected. It may be that algal calcite affected calculation of both the total shell thickness and percentage aragonite.

It is not surprising that variation within a shell increases with increasing age. Within a population, there are various microhabitats available, resulting in different rates of shell erosion and abrasion. The older the shell, the more time the shell will have been exposed to a variety of environmental factors influencing shell thickness.

\section{Carbonate Mineralogy}

Proportions of aragonite and calcite vary widely within most shells, with older carbonate having higher aragonite content than younger material. In addition, aragonite content increases across the shell away from the umbo, especially past the tremata, in part because of the shape of the shell. In abalone the shell profile is not a symmetrical arc; the shell thickness behind the tremata declines sharply toward the edge. The effect of a force perpendicular to the surface upon which the abalone is attached therefore has less abrasion effect per unit area of the sharply sloping shell, resulting in less shell wear and calcite removal. In addition, there is a distinct lip in the aragonite profile on the shell exterior. The lip is often smoothed over by a thick layer of calcite.

Overall aragonite content differed significantly among the three populations. Examination of the thickness of the shell layers from the Feigl's staining revealed (Figure 5) that, for all three populations, the "young" 
thickness of aragonite was very similar, in the range $1.10-1.30 \mathrm{~mm}$. In middle-aged shell, Moeraki shells did not show increased thickness of aragonite. However, the shells from Colac Bay and Waipapa had increases in the thickness of the aragonite to $2.30-2.50 \mathrm{~mm}$. The "old" shell from Moeraki had the thinnest aragonite layer for that age class. In addition, the calcitic outer layer was thinner than the "mid"-aged shell. In "old" shell sections, Colac Bay and Waipapa shells were very similar in aragonite thickness, approximately $2.90-3.10 \mathrm{~mm}$. It is thus the thickness of the outer calcite layer that caused the difference in proportion of aragonite and calcite between the populations. The environment probably controls much of the variation in mineralogic proportions. Perhaps abalone systematically accrete more calcite with increasing age, thus showing a decreasing proportion of aragonite.

It is interesting that the calcite layer in Waipapa "young" shell was the thickest of the three populations. Is it possible that as an adaptation to living in an exposed coastal area the abalone from Waipapa Point accrete a thicker layer of sacrificial calcite?

It is interesting to note the cost to the animal of producing and possessing a shell. There are at least three main costs of possessing a shell (Palmer 1992): energy for production of shell including the organic matrix, energy for transportation, and size limitation. In marine mollusks the costs of producing organic matrix alone can consume $10-60 \%$ of the energy spent on somatic growth and 0.15 to 1.5 times that of producing gametes (Palmer 1992).

Aragonite, due to its mechanical design, is considerably more resistant to crushing and boring by predators (Jackson et al. 1988) when compared with calcite. Aragonite is also more resistant to erosion. For example, the calcitic shell of Patella granatina has a higher rate of destruction than the aragonite-rich shell of $P$. argenvillei (Day et al. 2000). Why not manufacture the entire shell out of aragonite? One reason is the relatively high cost of production. Palmer (1992) found that a shell with only $1.5 \%$ organic material costs $22 \%$ of the total energy of shell produc- tion. In a shell with $5 \%$ organic material, this cost rises to $50 \%$ of total construction costs. Aragonite requires more organic material in construction, whereas calcite is comparatively thermodynamically stable and cheaper to construct but provides less structural strength. Second, calcite is $35 \%$ more resistant to shell dissolution in cold water (Taylor 1986). It is likely that the outer calcitic layer is accreted as a sacrificial means of protecting the stronger, more valuable inner aragonite. Mollusks can compensate to some extent for shell erosion by continuing to grow and thicken their shells (Day et al. 2000).

\section{Mineralogical Variability}

All populations of $H$. iris displayed a substantial amount of variation, perhaps due to growth pattern and age-related depositional history of the shell. In general younger shell shows a high degree of variation in aragonite content, perhaps due to the effect of erosion and other forms of shell damage such as shell borers (Shepherd et al. 1995b, Day et al. 2000). Young shell may be accreted at a similar rate among populations (Wells et al. 1998), but environmental factors erode the outer calcitic layer disproportionately, leaving older shell with a high aragonite content but lower variation.

The three populations showed significant and differing amounts of variation in aragonite content among shells (Table 2). In Colac Bay, older shell had a lower standard error relative to younger shell. Compared with the variation in the shell from Waipapa Point, however, the change in variation between young and old shell was small. Shells from Moeraki showed no clear trends in mineralogy or range. The largest amount of variation was around the umbo, where standard error was \pm 7.1 (Table 2). Some of this variation can be attributed to the effect of unremoved calcified algae. Waipapa shells had a low amount of variation in the older shell but a much higher amount of variation overall compared with the other populations, especially in younger shell (Table 2). A large proportion of the variation can be attributed to a single sample that had aragonite content 
considerably greater than the population average.

The high level of variability among specimens (and within them to a lesser extent) should be of concern when biogeochemical sampling is undertaken. High natural variation in mineralogy within and among abalone shells, and probably other bimineral mollusks, requires extensive subsampling and replication when assessing mineralogy. Many authors have reported mineralogy of a species based on a single measurement, sometimes of a single shell. This method may be satisfactory for a monomineralic, highly consistent species, but for a more complex species such as the highly variable bimineralic abalone $H$. iris far more samples must be taken to adequately characterize its mineralogy. Examination of the data from Figure 4 suggests that taking three or four shell sections representing different shell ages will yield almost as much information as the 4 by 5 grid used in this experiment.

We therefore suggest that a series of at least three shell sections, representing old, middle-aged, and young shell must be taken and analyzed to have any understanding of the true mineralogy of abalone shells. A single shell estimate, even from a very large number of shells, is unlikely to provide much information about mineralogy, especially if samples were taken from the same area of shell.

\section{Effects of the Environment}

The environments in which the shells formed are substantially different in terms of wave exposure. Waipapa Point is exposed to direct wave action, but the degree of wave action at Colac Bay is moderate in comparison. The population at Moeraki was fully sheltered, which not only had the effect of reducing the amount of "shell wear" but also provided an environment suitable for a wide variety of boring and encrusting organisms. The thick white algal layer found on shells (probably Mesophyllum printzianum) was analyzed using $\mathrm{XRD}$ and found to be calcitic. This species is prevalent in shallow reef habitats with a thick canopy of the macroalga Macrocystis pyrifera, which is a typical habitat at Moeraki (Naylor and McShane 1997). A second thinner coralline alga, Spongites yendoi, is more common in shallow, wave-exposed habitats that are typical of Waipapa Point and Colac Bay (Naylor and McShane 1997). Both layers reduce abrasion due to wave action; increasing calcitic layer thickness with decreasing wave exposure is the natural result.

Wave exposure appears to have little effect on the thickness of shells. Wells et al. (1998) found a similar lack of effect on predominantly soft body characteristics in $H$. iris, noting that there is little evidence for environmentally induced changes in condition indices relating to shell and soft body proportions. Only muscles in animals from waveexposed sites had a higher ability to work under anaerobic conditions, presumably during heavy wave action.

Seawater temperature at all three sites is similar, as is seasonal temperature range. The documented effects of seawater temperature on deposition of calcite and aragonite, with warmer water favoring aragonite production (Cohen and Branch 1992), thus had little effect in this study. In many mollusks, factors other than temperature may influence mineralogy, especially chemical or physical characteristics of the organic matrix, which are different for calcite and aragonite (Albeck et al. 1996, Falini et al. 1996), production of microgrowth patterns (Cerrato 2000), as well as the concentration of inorganic ions including $\mathrm{Mg}, \mathrm{Sr}$, and $\mathrm{PO}_{4}$ in seawater, salinity, and phylogenetic history (Cohen and Branch 1992).

Detailed data regarding seawater chemistry such as $\mathrm{pH}$, salinity, and elemental composition were not available for the southern New Zealand sites. However, all three sites were similar in adjoining land usage, were not immediately adjacent to large rivers or other freshwater sources, and are strongly influenced by the Southland Current, and therefore should be similar in seawater chemistry.

Shell boring occurs in many calcareous substrates such as mollusk shells, corals, and coralline algae (Sato-Okoshi and Okoshi 1996). Visual and SEM observations indicate that the shell-boring infestations in abalone 
are greater in the calcitic layers than in the aragonitic layers. This preference may create a bias in shell mineralogy toward a higher percentage of aragonite due to the removal of calcitic material.

The effect of a high degree of wave exposure on shell thickness in many gastropods is not as important as the effect of predators (Boulding et al. 1999). Therefore, in general, shells from sheltered shores, where predators such as crabs, lobsters, and some predatory fish live, are thicker and larger than shells from exposed locations (Boulding et al. 1999). However, as studies on littorinids show, the effect of wave action alone can differ greatly among closely related species. Fletcher (1995) demonstrated that the sympatric species Littorina obtusata and L. mariae had differing morphological responses to wave action. Shell strength decreased with increasing wave action in L. obtusata but increased in L. mariae.

There have been relatively few studies on the effects of predation on $H$. iris. The main predators of the abalone are the starfish $A s$ trustole scabra and Coscinasterias calamaria (McShane and Naylor 1997). Coscinasterias calamaria feeds predominately on the mussel Mytilus edulis (Day et al. 1995), but when there is a shortage of preferred food C. calamaria will feed on smaller abalone rather than on large ones (Day et al. 1995). The octopuses Octopus maorum and Robsonella australis may also prey upon abalone in low numbers in their usual habitat characterized by shallow, rocky pools (Gunson 1983). The haliotids have at least three responses to predators. The most obvious is the thick shell, but they also possess various escape behaviors and may even concentrate toxic chemicals in the mantle epithelium (Day et al. 1995). In addition, species of elasmobranchs and other species of fish that are important predators to other species of abalone are unimportant to H. iris (Schiel 1992). Abalone are reported to have a very low natural mortality $(M<0.1$ per year) (McShane and Naylor 1997). In modern times, the major predator of $H$. iris, as with most abalone worldwide, is Homo sapiens. The damage caused by people is twofold: removal of adult breeding animals and the return of undersized animals that may be either cut or not placed on a suitable substrate (Pirker 1992). In some instances, storm and other wave exposure-related events are a major source of abalone mortality (McShane and Naylor 1997).

\section{ACKNOWLEDGMENTS}

We appreciate assistance from Damian Walls for advice on XRD protocols and Anthony Reay for comments on the manuscript, both from the Department of Geology, University of Otago. Special thanks to Brian Nevin, Department of Mathematics and Statistics, University of Otago, for his statistical advice, and to the office of Global Education, Dickinson College for their support.

\section{Literature Cited}

Albeck, S., L. Addadi, and S. Weiner. 1996. Regulation of calcite crystal morphology by intracrystalline acid proteins and glycoproteins. Connect. Tissue Res. 35 (1-4): 365-370.

Balmain, J., B. Hannoyer, and E. Lopez. 1999. Fourier transformation infrared spectroscopy (FTIR) and X-ray diffraction analysis of mineral and organic matrix during heating of mother of pearl (nacre) from the shell of the mollusc Pinctada maxima. J. Biomed. Mater. Res. 48:749754.

Belcher, A. M., X. H. Wu, R. J. Christensen, P. K. Hansma, G. D. Stucky, and D. E. Morse. 1996. Control of crystal phase switching and orientation by soluble mollusc-shell proteins. Nature (Lond.) 381:56-58.

Bevelander, G. 1988. Abalone: Gross and fine structure. The Boxwood Press, Pacific Grove, California.

Bøggild, O. B. 1930. The shell structure of the molluscs. D. Kgl. Dan. Vidensk. Selsk. Skr. Naturvidensk. Og Mathem 9 (11): 232-325.

Boulding, E. G., M. Holst, and V. Pilon. 1999. Changes in selection on gastropod shell size and thickness with wave exposure on northeastern Pacific shores. J. Exp. Mar. Biol. Ecol. 232 (2): 217-239. 
Broad, T. 1996. An experimental approach to the culture of Mabe pearls in Paua (Haliotis iris) using recirculating and open aquaculture systems. M.S. thesis, Otago University, Dunedin, New Zealand.

Cairns, S. D., and I. G. MacIntyre. 1992. Phylogenetic implications of calcium carbonate mineralogy in the Stylasteridae (Cnidaria: Hydrozoa). Palaios 7:96-107.

Carriker, M. R. 1979. Ultrastructural effect of cleaning molluscan shell with sodium hypochlorite (Chlorox). Nautilus 93:47-51.

Carter, J. G., and G. R. Clark II. 1985. Classification and phylogenetic significance of molluscan shell microstructure. Pages 5071 in T. W. Broadhead, ed. Mollusks: Notes for a short course. Univ. Tenn. Dep. Geol. Sci. Stud. Geol. 13.

Cerrato, R. M. 2000. What fish biologists should know about bivalve shells. Fish. Res. (Amst.) 46 (1-3): 39-49.

Chateigner, D., C. Hedegaard, and H.-R. Wenk. 2000. Mollusc shell microstructures and crystallographic textures. J. Struct. Geol. 22:1723-1735.

Cohen, A., and G. Branch. 1992. Environmentally controlled variation in the structure and mineralogy of Patella granularis shells from the coast of southern Africa: Implications for palaeotemperature. Palaeogeogr. Palaeoclimatol. Palaeoecol. 91:4957.

Cropp, D., and D. O’Sullivan. 1994. Abalone pearls: A valuable product of abalone farming. Austasia Aquacult. 8 (1): 22-23.

Dauphin, Y., J. P. Cuif, H. Mutvei, and A. Denis. 1989. Mineralogy, chemistry and ultrastructure of the external shell layer in ten species of Haliotis with reference to Haliotis tuberculata (Mollusca: Archaeogastropoda). Bull. Geol. Inst. Univ. Upps., n.s. $15: 7-17$.

Davies, K. 1996. Tiny Stewart Island becomes source of priceless pearls. Natl. Business Rev., 14 June 1996, 30-32.

Davies, T. T., and P. R. Hooper. 1963. The determination of the calcite:aragonite ratio in mollusc shells by $\mathrm{X}$-ray diffraction. Miner. Mag. 33 (262): 608-612.

Day, E. G., G. M. Branch, and C. Viljoen. 2000. How costly is molluscan shell ero- sion? A comparison of two patellid limpets with contrasting shell structures. J. Exp. Mar. Biol. Ecol. 242:184-208.

Day, R., A. Dowell, G. Sant, J. Klemke, and C. Shaw. 1995. Patchy predation: Foraging behaviour of Coscinasterias calamaria and escape responses of Haliotis rubra. Mar. Freshwater Behav. Physiol. 26 (1): 11-33.

Dytham, C. 1999. Choosing and using statistics: A biologist's guide. Blackwell Science Ltd., London.

Erasmus, J., P. A. Cook, and N. Sweijd. 1994. Internal shell structure and growth lines in the shell of the abalone Haliotis midae. J. Shellfish Res. 13 (2): 493-501.

Falini, G., S. Albeck, S. Weiner, and L. Addadi. 1996. Control of aragonite or calcite polymorphism by mollusk shell macromolecules. Science (Washington, D.C.) 271:67-69.

Fankboner, P. 1991. Pearl culture in abalone. INFOFISH Int. 4 (91): 52-55.

1994. Process for producing pearls in abalone and other shell-bearing Molluska and nucleus used therewith. U.S. Patent.

Fassler, R. 1998. Opportunities for investing in pearl farming. World Aquacult. March, 6-13.

Fletcher, C. R. 1995. Microgeographical variation in shell strength in the flat periwinkles Littorina obtusata and Littorina mariae. Hydrobiologia 309:73-87.

Fritz, M., A. Belcher, M. Radmacher, D. Walters, P. Hansma, G. Stucky, D. Morse, and S. Mann. 1994. Flat pearls from biofabrication of organized composites on inorganic substrates. Nature (Lond.) 371:49-51.

Gaffey, S. J., and C. E. Bronnimann. 1993. The effects of bleaching on organic and mineral phases in biogenic carbonates. J. Sediment. Petrol. 63 (4): 752-754.

Giles, R., S. Manne, S. Mann, D. E. Morse, G. D. Stucky, and P. K. Hansma. 1995. Inorganic overgrowth of aragonite on molluscan nacre examined by atomic force microscopy. Biol. Bull. (Woods Hole) 188:8-15.

Gray, B. 1998. The value of aged seaweeds (Macrocystis pyrifera and Gracilaria chilensis) as feeds for the black-foot abalone ( $\mathrm{Ha}$ - 
liotis iris). M.S. thesis, University of Otago, Dunedin, New Zealand.

Gunson, D. 1983. Collins guide to the New Zealand seashore. William Collins Publishers Ltd., Auckland.

Hahn, K. O. 1989. Survey of the commercially important abalone species in the world. Page 348 in K. O. Hahn, Handbook of culture of abalones and other marine Gastropoda. CRC Press, Boca Raton, Florida.

Harper, E. M. 1997. The molluscan periostracum: An important constraint in bivalve evolution. Palaeontology (Lond.) 40 (1): 71-97.

Hawkes, G. P., R. W. Day, M. W. Wallace, K. W. Nugent, A. A. Bettiol, D. N. Jamieson, and M. C. Williams. 1996. Analyzing the growth of mollusc shell layers, in situ, by cathodoluminscence microscopy and raman spectroscopy. J. Shellfish Res. 15 (3): 659-666.

Hedegaard, C., and H.-R. Wenk. 1998. Microstructure and texture patterns of mollusc shells. J. Molluscan Stud. 64:133-136.

Jackson, A. P., J. F. V. Vincent, and R. M. Turner. 1988. The mechanical design of nacre. Proc. R. Soc. Lond. B. Biol. Sci. 234:415-440.

Kaplan, D. 1998. Mollusc shell structures: Novel design stratagies for synthetic materials. Curr. Opin. Solid State Mater. Sci. 3:232-236.

Lewis, D. W., and D. McConchie. 1994. Analytical sedimentology. Chapman \& Hall, New York.

Litivin, A. L., D. L. Kaplan, and C. Sung. 1997. Microstructure of aragonite growth at an air-liquid interface. J. Mater. Sci. 32:2233-2236.

Lowenstam, H. A. 1954. Factors affecting the aragonite:calcite ratios in carbonate secreting marine organisms. J. Geol. 62:284322.

Lowenstam, H. A., and S. Weiner. 1989. On biomineralization. Oxford University Press, New York.

McShane, P. E., and R. Naylor. 1997. Direct estimation of natural mortality of the New Zealand abalone, Haliotis iris. N. Z. J. Mar. Freshwater Res. 31:135-137.
Moore, D. M., and R. C. Reynolds. 1997. Xray diffraction and the identification and analysis of clay minerals. Oxford University Press, Oxford.

Mutvei, H. 1983. Ultrastructural evolution of molluscan nacre. D. Reidel Publishing Co., Dordrecht, the Netherlands.

Nakahara, H. 1982. Calcification of gastropod nacre. Pages 225-230 in P. Westbroek and $\mathrm{E}$. W. de Jong, eds. Biomineralization and biological metal accumulation: Biological and geological perspectives. D. Reidel Publishing Co., Dordrecht, the Netherlands.

Naylor, J. R., and P. E. McShane. 1997. Predation by polychaete worms on larval and post-settlement abalone Haliotis iris (Mollusca: Gastropoda). J. Exp. Mar. Biol. Ecol. 214:283-290.

New Zealand Seafood Industry Council. 2000. Abalone (paua) - the world scene. Seafood N. Z. 8:46-47.

Palmer, A. R. 1992. Calcification in marine molluscs: How costly is it? Proc. Natl. Acad. Sci. U.S.A. 89:1379-1382.

Pirker, J. 1992. Growth, shell-ring deposition, and mortality of paua (Haliotis iris Martyn) in the Kaikoura region. M.S. thesis, Canterbury University, Christchurch, New Zealand.

Poore, G. C. B. 1972. The ecology of New Zealand abalones, Haliotis species (Mollusca: Gastropoda). 1. Feeding. N. Z. J. Mar. Freshwater Res. 6:11-22.

Saleuddin, A. S., and H. P. Petit. 1983. The mode of formation and the structure of the periostracum. Mollusca 4 (1): 199-233.

Sandberg, P. A. 1971. Scanning electron microscopy of cheilostome bryozoan skeletons: Techniques and preliminary observations. Micropaleontology 17 (2): 129151.

Sato-Okoshi, W., and K. Okoshi. 1996. Microstructure of scallop shells infested with young boring polychaete, Polydora variegata. Bull. Inst. Oceanogr. (Monaco) Spec. 14 (4): 203-207.

Schaffer, T. E., C. Ionescu-Zanetti, R. Proksch, M. Fritz, D. A. Walters, N. Almqvist, C. M. Zaremba, A. M. Belcher, B. L. Smith, G. D. Stucky, D. Morse, and 
P. K. Hansma. 1997. Does abalone nacre form by heteroepitaxial nucleation or by growth through mineral bridges? Chem. Mater. 9:1731-1740.

Schiel, D. 1992. The enhancement of paua (Haliotis iris Marytn) populations in New Zealand. Pages 474-484 in S. A. Sheperd, M. J. Tegner, and S. A. Guzmán del Proo, eds. Abalone of the world: Biology, fisheries and culture. Fishing New Books, Oxford.

Shen, X., A. Belcher, P. Hansma, G. Stucky, and D. Morse. 1997. Molecular cloning and characterization of Lustrin A, a matrix protein from shell and pearl nacre of $\mathrm{Ha}$ liotis rufescens. J. Biol. Chem. 51:3247232481.

Shepherd, S. A., D. Al-Wahaibi, and A. R. A. Azri. 1995a. Shell growth checks and growth of the Omani abalone Haliotis mariae. Mar. Freshwater Res. 46:575-582.

Shepherd, S. A., M. Avalos-Borja, and M. O. Quintanilla. 1995b. Toward a chronology of Haliotis fulgens, with a review of abalone shell microstructure. Mar. Freshwater Res. 46:607-615.

Smith, A., C. Nelson, and H. Spencer. 1998. Skeletal carbonate mineralogy of New Zealand bryozoans. Mar. Geol. 151:2746.

Sokal, R. R., and F. J. Rohlf. 1995. Biometry. W. H. Freeman \& Co., New York.

Stuart, M. D., and M. T. Brown. 1994. Growth and diet of cultivated black-footed abalone, Haliotis iris (Martyn). Aquaculture 127 (4): 329-337.

Taylor, P. D. 1986. Scanning electron microscopy of uncoated fossils. Palaeontology (Lond.) 29 (4): 135-143.

Tong, L., and G. Moss. 1989. New Zealand abalone culture-A success for research. Austasia Aquacult. Mag. 3 (6): 4-5.

Watabe, N. 1965. Studies on shell formation. XI. Crystal-matrix relationships in the inner layers of mollusk shells. J. Ultrastruct. Res. 12:351-370.

Weiner, S., and L. Addadi. 1991. Acific macromolecules of mineralized tissues: The controllers of crystal growth. Trends Biochem. Sci. 16:252-256. 1997. Design strategies in mineralized biological materials. J. Mater. Chem. 7 (5): 689-702.

Wells, R. M. G., P. E. McShane, N. Ling, R. J. Wong, T. O. C. Lee, and J. Baldwin. 1998. Effect of wave action on muscle composition, metabolites and growth indices in the New Zealand abalone, Paua (Haliotis iris), with implications for harvesting and aquaculture. Comp. Biochem. Physiol. B. Comp. Biochem. 119 (1): 129136.

Wilson, N. H. F. 1987. Reproduction and ecology of Haliotis iris and $H$. australis from Otago. M.S. thesis, University of Otago, Dunedin, New Zealand.

Wright, L. E., and H. P. Schwarcz. 1998. Stable carbon and oxygen isotopes in human tooth enamel: Identifying breast feeding and weaning in prehistory. Am. J. Phys. Anthropol. 106:1-18.

Zar, J. H. 1984. Biostatistical analysis. Prentice-Hall, Upper Saddle River, New Jersey.

Zaremba, C. C., A. M. Belcher, M. Fritz, L. Li, S. Mann, P. K. Hansma, D. E. Morse, J. S. Speck, and G. D. Stucky. 1996. Critical transitions in the biofabrication of abalone shells and flat pearls. Chem. Mater. 8:679-690. 